\title{
The role of US signal value in contingency, drug conditioning, and learned helplessness
}

\author{
MURRAY J. GODDARD \\ University of New Brunswick, Saint John, New Brunswick, Canada
}

\begin{abstract}
In Pavlovian conditioning, organisms can learn that a conditioned stimulus (CS) signals the delivery of an unconditioned stimulus (US). The present paper first reviews research showing that organisms can also learn that a stimulus, normally considered to be a US, signals the delivery of another US. Second, the paper shows how such signal value may contribute to three conditioning phenomena that are of interest to many psychologists: contingency, drug conditioning, and learned helplessness. In addition to showing how such signal value may contribute to these three phenomena, suggestions for further research, as well as current gaps in the knowledge base, are outlined.
\end{abstract}

In Pavlovian conditioning, a neutral conditioned stimulus (CS) signals a biologically potent unconditioned stimulus (US). Given that certain conditions are fulfilled, organisms show CS-US learning, as evidenced by the development of one or more conditioned responses (CRs) to the CS. The terminology of Pavlovian conditioning encourages the view that the CS is the signaling event and the US is the signaled event. However, there is now evidence that a stimulus, normally considered to be a US, can also be an effective signaling event.

The present paper first reviews research showing that organisms are capable of using a stimulus, normally considered to be a US, as a signal, or cue, for the delivery of another US. Second, the paper shows how such signal value may contribute to three conditioning phenomena that are of interest to many psychologists: contingency, drug conditioning, and learned helplessness. In addition to showing how such signal value may contribute to these three phenomena, suggestions for further research, as well as current gaps in the knowledge base, will be outlined.

\section{US SIGNAL VALUE}

\section{Introduction}

Research in Pavlovian conditioning has focused on CS-US learning, but there is evidence for what might be called US-US learning, in which a stimulus, normally considered to be a US, signals the delivery of the same, or a different, US (Figure 1).

\footnotetext{
This research was supported by grants from the Natural Sciences and Engineering Research Council of Canada (NSERC). I thank John Wixted and several anonymous reviewers who made many constructive suggestions on earlier versions of this manuscript. Correspondence should be addressed to M. J. Goddard, Department of Psychology, University of New Brunswick, Saint John, NB E2L 4L5, Canada (e-mail: goddard@unbsj.ca).
}

For example, Pavlov (1927) was one of the first to report conditioned salivation to a relatively weak electric shock when shock signaled the delivery of food (see also Dearing \& Dickinson, 1979; Dickinson \& Pearce, 1977; Pearce \& Dickinson, 1975). More recently, Tuber (1986) showed the acquisition of a conditioned forelimb response in cats when a brief shock to one forepaw predicted a shock to the opposite forepaw, and Schreurs and Alkon (1990) showed conditioning of the rabbit's nictitating membrane response when paraorbital electrical stimulation served as both CS and US (see also Gunther, Miller, \& Matute, 1997).

Further, even within Pavlovian conditioning, a US in one conditioning preparation may be considered a CS in another. For example, in appetitive conditioning, a light or tone (CS) may signal the delivery of a sucrose solution (US). However, in taste aversion learning, a sucrose solution (CS) may signal the delivery of an illness-inducing injection of lithium chloride (US). Therefore, while sucrose serves as a US in appetitive conditioning, it serves as a CS in taste-aversion learning. The conceptualization of taste-aversion learning as an example of US-US learning has been explicitly addressed by other learning researchers (Garcia, 1989; see also Flaherty, Coppotelli, Grigson, Mitchell, \& Flaherty, 1995, showing anticipatory contrast, in which intake of a lower valued solution is suppressed when paired with a higher valued solution).

Since it is clear that sucrose serves as a US in appetitive conditioning and a CS in taste-aversion learning, it may be inappropriate to refer to a stimulus as a CS or a US in any absolute sense. Rather, it may be more meaningful to refer to stimuli that act in the role of a CS or stimuli that act in the role of a US. Therefore, the term US signal value is somewhat of a misnomer; it may be more accurate to refer to the signal value of stimuli that ordinarily are considered to be USs. However, the term US signal value will be used in the present paper simply for ease of discussion; it is not meant to imply, however, that a particular stimulus in Pavlovian conditioning can be discretely categorized as only a CS or only a US. 


\section{CS - US Learning}

\author{
Tone (CS) $\rightarrow$ Food (US)
}

\section{US - US Learning}

\section{Shock (US) $\rightarrow$ Food (US)}

Figure 1. CS-US and US-US learning in Pavlovian conditioning.

\section{Appetitive Conditioning}

In studies from my laboratory, we have been investigating the signal value of food in an appetitive conditioning preparation with rats (Goddard, 1996, 1997, 1999; Goddard, Holland, O'Brien, \& Hansen, 1994). For example, in Goddard (1999), a single food pellet was delivered and then, $10 \mathrm{sec}$ later, three additional food pellets followed. Only one trial was given per session and subjects received 10 training sessions. Results showed that subjects rapidly learned this single food pellet-triple food pellet association and evidenced this learning by a significant increase in food cup, or magazine, entries after the single food pellet (Goddard, 1999). Further, after acquisition, the signal value of food showed extinction, when the single food pellet was no longer followed by additional pellets (Goddard, 1999), and, after extinction, showed spontaneous recovery; that is, responding recovered to the single food pellet when a 24-h time period intervened after extinction (Goddard, 1997).

The signaling properties of food have also been studied in appetitive conditioning by Capaldi and his associates (Capaldi 1994; Capaldi, Alptekin, \& Birmingham, 1997; Capaldi, Alptekin, Miller, \& Birmingham, 1997; Capaldi \& Birmingham, 1998). For example, in Capaldi, Alptekin, and Birmingham (1997), the number of food pellets delivered in a one-way runway apparatus on Trial 1 indicated whether reward or nonreward would occur on Trial 2. Results showed that discriminative responding on Trial 2 was much better the larger the difference in reward magnitude between the two trials (Capaldi, Alptekin, \& Birmingham, 1997). There is now evidence that reward-produced memories may serve an important signaling function in discrimination learning and extinction (Capaldi \& Birmingham, 1998).

\section{Aversive Conditioning}

The signal value of shock has also been studied in an aversive conditioning preparation. For example, Crowell (1974) showed that when rats received a weak shock paired with a strong shock, the aversive properties of the weak shock were increased. More recently, Anderson, Crowell, DePaul, and McEachin (1997) showed that subjects formed a shock onset-strong shock association when a prolonged-duration shock was delivered. That is, a prolonged-duration shock actually consisted of two parts: (1) shock onset, which may be considered analogous to the weak shock in Crowell; and (2) the ongoing painful effects of the prolonged shock, which may be considered analogous to the strong shock in Crowell. The idea that subjects form a stimulus onset-strong stimulus association when a prolonged-duration US is delivered is a useful concept that will be discussed in more detail later (see also Stein, 1966, for a discussion of how stimulus onset may come to signal later, more prolonged, stimulus effects).

\section{Blocking and Overshadowing}

In Kamin's (1968) classic blocking study, rats received noise-shock trials prior to receiving a simultaneous presentation of noise and light followed by shock. Conditioning to the light was poor; that is, the noise-shock association "blocked" the light-shock association from forming. Similarly, there is also evidence that the signal value of a stimulus normally considered to be a US can block CS conditioning. For example, we have shown that when pigeons first received trials in which food signaled a second food delivery, conditioning to a keylight CS was blocked when the keylight subsequently signaled the second food delivery (Goddard \& Jenkins, 1988; see also Lambos, 1986). A similar outcome has also been shown in a food conditioning preparation with rats (Egger \& Miller, 1963; Goddard et al., 1994). There was also evidence that pigeons were using the first food delivery to time the approximate arrival of the second food delivery, especially with shorter inter-US intervals (see, e.g., Goddard \& Jenkins, 1988, Experiment 1). In CS-US learning, subjects may also use a CS to time the approximate arrival of the US (see, e.g., Cole, Barnett, \& Miller, 1995).

In overshadowing, Kamin (1969) showed that when rats received a simultaneous presentation of a weak noise and light prior to shock, conditioning to the weak noise was reduced relative to that in a control condition in which rats received only weak noise-shock trials. Similarly, there is evidence that the signal value of a stimulus normally considered to be a US can also overshadow CS conditioning. For example, in a study by Best and Gemberling (1977), rats received a taste CS followed (after a delay) by the identical taste CS prior to an illness-inducing injection of lithium chloride. By manipulating the delay between the first and second CSs, Best and Gemberling showed that at shorter (but not longer) intervals, the first CS overshadowed the second CS-illness association. Notably, overshadowing in Best and Gemberling was shown in only one trial; other studies have also shown one-trial overshadowing in Pavlovian conditioning (Mackintosh, 1971; Mackintosh \& Reese, 1979). In a similar vein, rats showed poor taste-aversion learning in a single US-CS-US conditioning sequence when the interval 
between the first US and the CS was shorter, rather than longer (Best \& Domjan, 1979; Cannon, Berman, Baker, \& Atkinson, 1975; Domjan, 1978; Domjan \& Best, 1977). This so-called proximal US preexposure effect may result because the signal value of a stimulus normally considered to be a US overshadows CS conditioning.

\section{The Preparatory Releaser Procedure}

The signal value of a stimulus normally considered to be a US is also well known in the preparatory-releaser procedure (Konorski \& Lawicka, 1959; see also Bottjer \& Hearst, 1979; Goddard \& Holland, 1996, 1997; Holland \& Forbes, 1982; Reberg \& Memmott, 1979; Terry $\&$ Wagner, 1975). In the preparatory-releaser procedure, a "preparatory" US signals that a stimulus will (in featurepositive training), or will not (in feature-negative training), subsequently be reinforced. Such reinforcement may be delivered independently of responding in a Pavlovian paradigm or contingent on responding in an operant paradigm. For example, in an operant feature-positive paradigm (Goddard \& Holland, 1996), rats were reinforced for leverpressing to a tone only when the tone had been preceded $30 \mathrm{sec}$ earlier by the delivery of a flavored sucrose solution. When the tone was presented alone, leverpressing was not reinforced. Significant feature-positive learning was achieved in approximately 20 training sessions and was comparable to a condition in which a light (rather than flavored sucrose) served as the conditional cue. Conversely, in an operant feature-negative paradigm (Goddard \& Holland, 1997), rats were not reinforced for leverpressing to a tone when the tone had been preceded $30 \mathrm{sec}$ earlier by a flavored sucrose solution. When the tone was presented alone, however, leverpressing was reinforced. Surprisingly, feature-negative learning was shown in fewer than five training sessions and was significantly more rapid than a condition in which a light (rather than flavored sucrose) served as the conditional cue (for further discussion, see Goddard \& Holland, 1997). Thus, there is evidence that a stimulus normally considered to be a US may serve a modulatory role in the preparatory-releaser procedure. Further, the use of such "nontraditional" features may provide insight into general conditioning and modulatory learning processes (Skinner, Goddard, \& Holland, 1998).

\section{US-US Learning Obeys Two Fundamental Associative Principles}

In summary, thus, there is evidence that organisms are capable of using a stimulus normally considered to be a US as a signal, or cue, for the delivery of another US. Perhaps, in hindsight, this is not particularly surprising since US-US learning obeys two fundamental associative principles in Pavlovian conditioning. First, it has long been known that CS-US learning is facilitated when the CS is increasingly more intense, or distinctive, relative to the ambient environment (see, e.g., Kamin, 1965; Kamin \& Schaub, 1963). In US-US learning, the signaling US is surely as intense as many standard CSs. Second, it has long been known that CS-US learning is facilitated with more similar stimuli. For example, Testa (1975) showed that CS-US learning was facilitated when rats received a ceiling light paired with an air blast originating from the ceiling, or a floor light paired with an air blast originating from the floor, relative to conditions in which the location of the light and air blast differed. Using an experimental design that carefully controlled for several alternative interpretations, Rescorla and Furrow (1977) also showed that second-order conditioning was facilitated with more similar first- and second-order stimuli. Since, in US-US learning, the signaling US may be similar, or even identical, to the signaled US, US-US learning may show a benefit in similarity not shared by CS-US learning. Thus, US-US learning obeys two fundamental associative principles in Pavlovian conditioning: (1) The signaling stimulus is an intense and distinctive event, and (2) the signaling and signaled event may be similar, or even identical, to each other.

\section{THE ROLE OF US SIGNAL VALUE IN CONTINGENCY}

\section{CS-US Conditioning and the US Delivery Schedule}

In the studies cited above, researchers specifically examined an organism's ability to use a stimulus normally considered to be a US as a cue for subsequent US delivery. However, in a conventional Pavlovian conditioning study, a researcher may not realize that the stimulus nominally used as the US may acquire a signaling role. In part, such a signaling role may result because several CS-US trials are presented in a daily session, and the US delivery schedule may contain systematic regularities.

For example, consider a study of CS-US learning in which subjects receive several CS-US trials in a daily session with one CS-US trial separated from another by an intertrial interval (ITI). This ITI may be fixed (e.g., subjects may receive light-food pairings once a minute) or variable (e.g., subjects may receive light-food pairings at variable ITIs that average once a minute). Several researchers have noted that subjects may anticipate food delivery not only by forming a light-food association but also by using food delivery to time the approximate arrival of subsequent food delivery (see, e.g., Jenkins, Barnes, \& Barrera, 1981). Additionally, the delivery of a US may predict a subsequent US-free period when there is some minimum ITI between USs (see, e.g., Goddard, 1995). Presumably, any systematic regularities in the US delivery schedule could be minimized with only one CS-US trial in each daily session; however, multitrial, rather than single-trial, procedures tend to be the norm in Pavlovian conditioning.

There is evidence that subjects can detect systematic regularities in the US delivery schedule during CS-US conditioning. For example, Davis, Shattuck, and Wright (1981) found that when rats received tone-shock pairings with a minimum ITI of $3 \mathrm{~min}$, the rats showed both 
response suppression during the tone and response acceleration in the 1st minute following shock. That is, subjects evidenced learning a tone-shock relation (responding during the tone was suppressed) while simultaneously learning a shock-no shock relation (responding after shock was increased). Davis et al. (1981) presented additional evidence that this post-shock response increase resulted because shock delivery predicted a subsequent "safety" period free from shocks (and was not simply the recovery of suppressed responding), since post-shock responding increased relative to baseline levels. Davis, Memmott, and Hurwitz (1975) have pointed out several additional examples of the powerful behavioral control exerted by a systematic relationship in the US delivery schedule that may be unintended by the researcher, but rapidly discovered by the subject (see also Davis, Herrman, MacFadden, \& Ellen, 1977; Davis \& Memmott, 1984; Goddard, 1995).

\section{CS-US Contingency}

Perhaps the most convincing demonstration that organisms are sensitive to the CS-US contingency in Pavlovian conditioning comes from a study by Rescorla (1968). In Rescorla's study, one group of rats received CS-US pairings, and another group received the same number of CS-US pairings but additional USs were delivered in the session. Because these additional USs were delivered in such a way that US probability was identical when the CS was on or off, the CS-US contingency equaled zero. Results showed that the delivery of additional USs impaired CS-US learning, even though the number of temporally contiguous CS-US pairings was identical in both groups. Other researchers have also shown that adding USs in a session impairs CS-US learning, even though the number of temporally contiguous CS-US pairings was not affected by such a manipulation (see, e.g., Durlach, 1983; Goddard \& Jenkins, 1987). While there is disagreement as to why organisms are sensitive to contingency (see, e.g., Alloy \& Tabachnik, 1984; Gibbon, 1981; Goddard \& Allan, 1988; Miller \& Matzel, 1988; Rescorla \& Wagner, 1972), there is reasonable agreement that contingency is an important procedural variable in Pavlovian conditioning (but see Papini \& Bitterman, 1990). An agreement on the procedural importance of contingency in Pavlovian conditioning has also filtered down to introductory psychology, as well as advanced learning, texts (see, e.g., Atkinson, Atkinson, Smith, Bem, \& Nolen-Hoeksema, 1996; Gleitman, 1995; Klein, 1996; Schwartz \& Robbins, 1995).

\section{Contingency Manipulations Alter the US Delivery Schedule}

Note, though, that when the CS-US contingency is reduced by adding USs in a session, the US delivery schedule is altered. Specifically, when additional USs are delivered in a conditioning session, the interval between USs is also reduced - an outcome that has been pointed out by other learning researchers (see, e.g., Jenkins \&
Shattuck, 1981). It is possible, therefore, that as this interUS interval is shortened, subjects may come to anticipate US delivery on the basis of the time following a prior US, rather than on the basis of the CS. Although no systematic regularities in the US delivery schedule may be intended, there is often some minimum inter-US interval (see, e.g., Durlach, 1983; Goddard \& Jenkins, 1987); further, CS-US noncontingency typically requires the delivery of a large number of USs in a protracted session (see, e.g., Ayres, Benedict, \& Witcher, 1975; Dweck \& Wagner, 1970; Gamzu \& Williams, 1973). Thus, impaired CS-US learning when USs were added to a session may result because the US delivery schedule was altered; the reduction in contingency caused by such a manipulation may not be particularly important.

\section{A Critical Test of Contingency}

Unfortunately, adding USs in a session alters both contingency and the US delivery schedule, so it is difficult to know which variable is more important. What is needed is a study in which adding USs reduces contingency but the altered US delivery schedule facilitates (rather than impairs) CS-US learning. If contingency is critical, CS-US learning should continue to be impaired; if the altered US delivery schedule is critical, CS-US learning should be facilitated.

In fact, such a critical test of contingency was conducted by Goddard et al. (1994). An outline of the experiment is shown in Figure 2.

In both Group No Extra (NE) and Group Extra Unsignaled (EU), rats received training with a systematic relation in the food delivery schedule prior to CS-US training. In Group NE, a string of 10 food pellets was presented midway in the session so that a food pellet was a reliable cue that a subsequent pellet would follow in $10 \mathrm{sec}$. After 20 training sessions with such a systematic
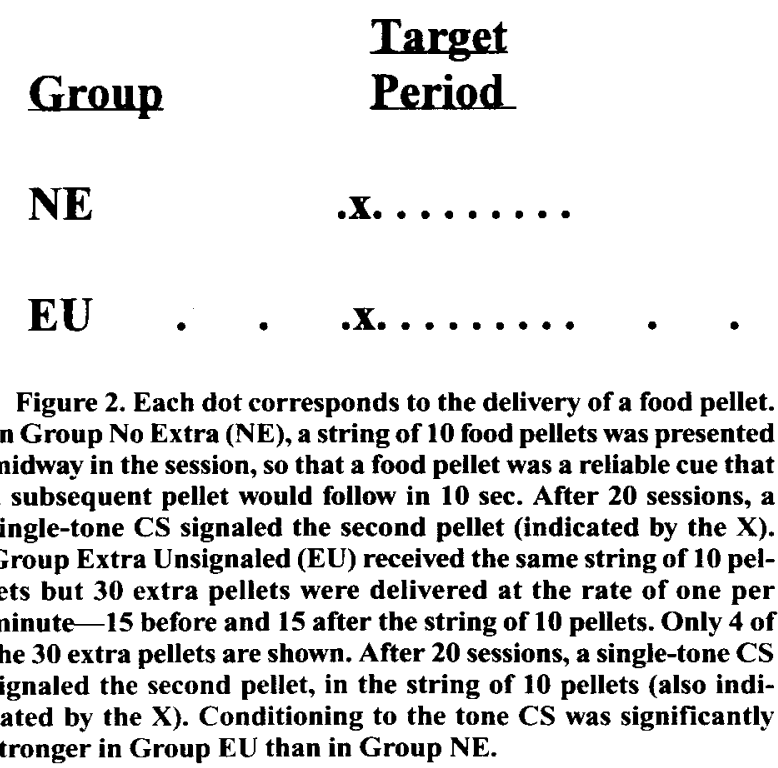
food delivery schedule, a single-tone CS signaled the second pellet. Presumably, in Group NE, CS-US learning should be blocked by the prior establishment of food as a reliable signal, or cue, for the delivery of another food pellet in $10 \mathrm{sec}$ (Goddard \& Jenkins, 1988).

In Group EU, a string of 10 pellets was also presented midway in the session, but 30 extra pellets were delivered at the rate of 1 per minute- 15 before and 15 after the string of 10 pellets. After 20 sessions, a single-tone CS signaled the second pellet (in the string of 10 pellets). Note that in Group EU, a food pellet was not a reliable cue that a subsequent pellet would follow in $10 \mathrm{sec}$, since pellets were more frequently separated by $1-\mathrm{min}$, rather than 10 -sec, inter-US intervals. Simply stated, it would be difficult for subjects to "know" that a subsequent pellet would follow in $10 \mathrm{sec}$ when the food pellet just prior to the CS was delivered in Group EU. Thus, CS-US learning should be better in Group EU even though the CS-US contingency was lower in Group EU than in Group NE. Note that in both groups, the probability of a US given a CS equaled 1.0, but the probability of a US given no CS was higher in Group EU. Results showed significantly stronger CS-US learning in Group EU (Goddard et al., 1994). A similar result has been shown in an autoshaping preparation with pigeons (Goddard \& Jenkins, 1988) and a secondary reinforcement procedure with rats (Egger \& Miller, 1963).

These results suggest that adding USs can impair CS-US learning not because contingency is altered but because the US delivery schedule is altered. However, the Goddard et al. (1994) study differed in certain ways from traditional contingency studies. For example, training with a systematic relation in the US delivery schedule was given prior to CS-US training, whereas, in many studies of contingency, learning of any systematic regularities in the US delivery schedule presumably occurs simultaneously with CS-US training. Future studies that vary the US delivery schedule during CS-US training are needed (but see Egger \& Miller, 1963). Further, the Goddard et al. study presented only one CS-US trial per session whereas in traditional contingency studies, several trials are typically given. Future studies that parametrically manipulate the number of trials per session are needed.

\section{The Trial Spacing Effect}

There is an additional effect, however, that suggests that an altered US delivery schedule, and not contingency, may contribute to the attenuated responding shown when additional USs are delivered in a conditioning session. This is the so-called trial spacing effect, in which CS-US learning is impaired with shorter ITIs (Gibbon, Baldock, Locurto, Gold, \& Terrace, 1977; Gibbon, Locurto, \& Terrace, 1975; Jenkins et al., 1981; Perkins et al., 1975; Prokasy, Grant, \& Myers, 1958). For example, in one study of the trial spacing effect, pigeons showed significantly poorer learning when light-food pairings were presented at 30 -sec, rather than 5-min, fixed ITIs. Further, impaired learning persisted even after subjects received extensive light-food conditioning (Jenkins et al., 1981, Experiment 1).

Note that in the trial spacing effect, ITI manipulations do not alter CS-US contingency since US probability when the CS is on and off is not changed. Further, sustained and persistent impairments in CS-US learning, at shorter fixed ITIs, makes it unlikely that subjects would have learned the contingency "if only they had been given more time," or more exposure, to the training regime.

However, as previously noted, subjects may anticipate US delivery not only by forming a CS-US association but also by using a stimulus normally considered to be a US to time the approximate arrival of a subsequent US (Goddard, 1991; Jenkins et al., 1981). As the possibility for this timing is facilitated with shorter fixed ITIs, CS-US learning may be progressively impaired.

If subjects use a stimulus normally considered to be a US to time the approximate arrival of a subsequent US, the trial spacing effect should be more robust with fixed, rather than variable, ITIs. That is, as the ability of an organism to time US delivery is impaired by variations in the inter-US schedule, the predictive value of the CS increases and CS-US learning should improve. In fact, there is evidence showing that the trial spacing effect is more robust at fixed, rather than variable, ITIs even when the number of CS-US pairings, session length, and average ITI are equated (see, e.g., D. S. Mitchell, 1974; Nageishi \& Imada, 1974; Prokasy, 1965; Salafia, Mis, Terry, Bartosiak, \& Daston, 1973; van Hest, van Haaren, Kop, \& van der Schoot, 1986). Thus, the trial spacing effect provides converging evidence that an altered US delivery schedule, and not contingency, may be responsible for attenuated CS-US conditioning when USs are added to a conditioning session.

\section{The Rescorla-Wagner Model and \\ Scalar Expectancy Theory}

Two major theoretical accounts of contingency and the trial spacing effect are the Rescorla-Wagner model (Rescorla \& Wagner, 1972) and scalar expectancy theory (SET) (Gibbon \& Balsam, 198l, see also Jenkins et al., 1981). According to the Rescorla-Wagner model, adding USs in a session impairs CS-US learning because USs condition context, and the context can better block CS-US learning. Thus, when USs are added in a contingency manipulation, context conditioning increases and better blocks CS-US learning; when the ITI is shortened in a trial spacing manipulation, context extinction is impaired and context can, again, better block CS-US learning.

According to SET, performance to a CS is determined by a ratio between US expectancy in the background, or cycle $(\mathrm{C})$, and US expectancy during a trial (T). When the $\mathrm{C} / \mathrm{T}$ ratio is above some minimal value (normally $2 / 1$; see Gibbon, 1981, p. 292), conditioned responding emerges. According to SET, adding USs in a session, or shortening 
the ITI, reduces responding by similarly increasing US expectancy in the background and lowering the $\mathrm{C} / \mathrm{T}$ ratio.

Note, though, that neither theory in its current form predicts the critical test of contingency shown by Goddard et al. (1994), in which conditioned responding was improved by adding extra USs. In addition, neither theory provides a particularly good explanation for why the trial spacing effect is facilitated with fixed, rather than variable, ITIs. For example, according to SET, because fixed and variable ITIs maintain the same average cycle time and result in the same $\mathrm{C} / \mathrm{T}$ ratio, equivalent responding should result. With the Rescorla-Wagner model, certain post hoc assumptions would be necessary in which a combination of shorter and longer ITIs improves context extinction more than a constant, intermediate ITI. Arguably, however, the Rescorla-Wagner model does not provide a particularly good explanation for the sustained and persistent impairments in responding shown with short ITIs anyway since, with extended training, contextual associative strength should extinguish and responding should improve. But, as previously noted, an important characteristic of the trial spacing effect is the sustained and persistent impairments in responding shown with short ITIs.

This does not necessarily imply, however, that the Rescorla-Wagner model or SET could not be modified to account for Goddard et al.'s (1994) results. For example, the Rescorla-Wagner theory might suggest that timecorrelated post-US cues can block CS associative strength. Therefore, in Group EU, spaced USs extinguished the associative strength of these post-US cues, which attenuated blocking and resulted in better CS conditioning. Note, though, that the addition of spaced USs in Group EU also conditioned context that acted to block CS conditioning. Therefore, a revised Rescorla-Wagner model would need to specify the amount of CS conditioning expected when additional spaced USs (1) extinguish the time-correlated post-US cues (which act to improve CS conditioning), but (2) condition context (which acts to impair CS conditioning).

The advantage of the present account, however, is that standard contingency manipulations, manipulations showing that adding USs can facilitate conditioning independently of contingency (Goddard et al., 1994), the trial spacing effect, and the dependence of the trial spacing effect on fixed, rather than variable ITIs, can all be seen as examples of a single process in which a stimulus normally considered to be a US signals subsequent US delivery.

\section{THE ROLE OF US SIGNAL VALUE IN DRUG CONDITIONING}

\section{Introduction}

Pavlov (1927) was one of the first researchers to suggest that the typical administration of a drug resembles classical conditioning. That is, those procedures, or en- vironmental cues, that reliably precede drug delivery may serve as the CS and the actual drug administration may serve as the US. In both infrahumans and humans, Pavlovian conditioning has been shown to make an important contribution to drug effects, especially drug tolerance (Hinson \& Siegel, 1982; Siegel, 1983, 1990; Siegel \& Allan, 1998; Siegel, Krank, \& Hinson, 1987; Stewart, 1992).

\section{Alcohol Studies}

Many Pavlovian drug conditioning studies use alcohol as the drug US. As a US, alcohol elicits a number of physiological responses, including hypothermia, or a reduction in body temperature. When a CS signals the delivery of alcohol, the compensatory CR consists of hyperthermia, or an increase in body temperature. The acquisition of such a CR may result in alcohol tolerance (the progressive diminution in the effects of alcohol) and alcohol "craving" (a desire for alcohol experienced in the presence of those cues that previously signaled alcohol delivery). Although associative contributions to tolerance do not necessarily imply compensatory CRs (see, e.g., Wagner \& Brandon, 1989), there is considerable evidence that compensatory CRs contribute to alcohol tolerance and "craving" in infrahumans and humans (see, e.g., Blakey \& Baker, 1980; Crowell, Hinson, \& Siegel, 1981; Hodgson, Rankin, \& Stockwell, 1979; Jones, 1974; Le, Poulos, \& Cappell, 1979; Ludwig \& Stark, 1974; Mansfield \& Cunningham, 1980; Mathew, Claghorn, \& Largen, 1979; Melchior \& Tabakoff, 1981).

\section{"Binge" Drinking}

In "binge" drinking, an individual may spend long periods of time alcohol-free; however, the ingestion of a small amount of alcohol seems to elicit additional ingestion (Jellinek, 1960). Note that in binge drinking, a small amount of alcohol reliably precedes the delivery of additional alcohol; a possibility that has been suggested by other researchers (see, e.g., Greeley, Le, Poulos, \& Cappell, 1984). The presence of a small dose-large dose relation in binge drinking resembles Goddard's (1999) finding that rats learned a single food pellet-triple food pellet association in appetitive conditioning, as well as Crowell's (1974) finding that rats learned a weak shockstrong shock association in aversive conditioning.

To test the possibility that subjects can learn a small dose-large dose relation with alcohol, Greeley et al. (1984) exposed experimental rats to a low alcohol dose followed by a high alcohol dose. Control rats received the identical administrations of low and high alcohol doses but in an explicitly unpaired relationship. Results showed a stronger compensatory CR of hyperthermia following the low alcohol dose and increased tolerance to the high alcohol dose in experimental relative to control subjects. Further, conditioned hyperthermia and tolerance were extinguished when experimental subjects were given repeated injections of the low alcohol dose 
alone, in the absence of the high alcohol dose (Greeley et al., 1984). Note that in this extinction procedure, alcohol tolerance was paradoxically extinguished by alcohol delivery.

The study by Greeley et al. (1984) is noteworthy for at least three reasons. First, the study suggests that, with alcohol, an explicit low dose-high dose relation can be learned and that, once learned, the delivery of a low dose may contribute to alcohol "craving." There is evidence that in heavy, or binge, drinking (in which a low dosehigh dose relation may be present), a low dose of alcohol may elicit alcohol craving (see, e.g., de Wit \& Chutuape, 1993; Hodgson et al., 1979; Ludwig, Wikler, \& Stark, 1974; Marconi, Fink, \& Moya, 1967; Stein, Niles, \& Ludwig, 1968). Second, the study suggests that periodic deliveries of a low dose of alcohol (in the absence of additional alcohol) may help stop heavy drinking, a prediction that has some empirical support (see, e.g., Faillace, Flamer, Imber, \& Ward, 1972; Hodgson \& Rankin, 1976; Paredes, Gregory, \& Jones, 1974; Paredes, Hood, Seymour, \& Gollob, 1973). Finally, if low dosehigh dose learning occurs with alcohol, it is possible that low dose-high dose learning may occur with other drugs. In fact, there is evidence for so-called drug priming effects, in which, after prolonged administration of high drug doses, a low drug dose elicits a wide variety of drugseeking behaviors (for a recent review, see de Wit, 1996).

It is certainly clear, however, that the present account cannot provide a complete explanation for binge drinking. For example, the present account is simply silent on why a binge drinker ingests a small amount of alcohol to begin with. However, the present account suggests that the signal value of a small drug dose may make a contribution to binge drinking and drug "priming" effects in humans.

\section{Drug-Drug Learning}

There is also evidence that drug-drug learning occurs when the signaling and signaled drugs differ (see, e.g., Lett, 1983; S. H. Mitchell, de Wit, \& Zacny, 1995; Revusky, 1985; Taukulis, 1982, 1986, 1996). For example, Taukulis (1986) showed that the drug atropine sulfate elicited conditioned hyperthermia when paired with another drug eliciting hypothermia (sodium pentobarbital). Further, Taukulis (1986) showed that such conditioned hyperthermia was unlikely to have been mediated by increased locomotion, since atropine sulfate attenuated sodium-pentobarbital-induced hypothermia even in unconscious subjects.

It is possible that drug-drug learning has clinical implications when physicians, psychiatrists, or psychologists administer a particular combination of two or more drugs to a patient. Since any unintended associative relationship between drugs may alter a drug's properties, the effects of a drug paired in an associative relation with another drug may be quite different from the effects of a drug presented alone.

\section{THE ROLE OF US SIGNAL VALUE IN LEARNED HELPLESSNESS}

\section{Introduction}

Preexposure to inescapable shock leads to greater escape and avoidance learning deficits than does preexposure to escapable shock (Seligman \& Maier, 1967). One theoretical explanation of such an effect is learned helplessness (Maier, 1989; Maier, Seligman, \& Solomon, 1969; Seligman, Maier, \& Solomon, 1971). According to learned helplessness, organisms learn that there is no contingency between responding and shock termination when preexposed to inescapable shock. This cognitive expectation of response-shock noncontingency has two consequences: (1) It reduces an organism's motivation to respond (i.e., it results in a response initiation deficit); and (2) it subsequently interferes with the learning of a response-shock contingency (i.e., it results in a cognitive deficit) (Maier, 1989).

\section{The Punishment Intensification Effect}

Preexposure to inescapable shock also leads to the socalled punishment intensification effect. In the punishment intensification effect, preexposure to prolonged inescapable shock facilitates the ability of brief shock to punish responding (Anderson, 1966, 1993; Anderson, Cole, \& McVaugh, 1968; Anderson et al., 1997; Hollis \& Overmier, 1973; Kurtz \& Pearl, 1960; Pearl, Walters, \& Anderson, 1964; Walters \& Rogers, 1963). For example, in one study of the punishment intensification effect, Anderson et al. (1997), showed that rats preexposed to inescapable 3-min shocks showed less drinking when drinking was subsequently punished by 0.5 -sec shocks than did rats not given such preexposure. Note that the punishment intensification effect runs counter to learned helplessness theory since preexposure to inescapable shock facilitates (not impairs) subsequent response-shock learning. Further, the punishment intensification effect is likely not due to temporary fear sensitization, since the effect persists with a delay between preexposure and training of 13 days (Anderson et al., 1968) or even 1 year (Walters \& Rogers, 1963). It is possible that psychologists are less familiar with the punishment intensification effect since introductory psychology, as well as advanced learning, texts often discuss learned helplessness theory but tend to omit discussion of the punishment intensification effect (see Atkinson et al., 1996; Gleitman, 1995; Klein, 1996; Schwartz \& Robbins, 1995).

There is evidence that the punishment intensification effect results because shock onset is made more aversive because it is paired with the delivery of prolonged and intense shock. Since, as previously described, weak shock is made more aversive when paired with strong shock (Crowell, 1974), brief shock will more effectively punish responding when brief shock has been paired with the delivery of prolonged and intense shock. In support, after preexposure to prolonged inescapable shock, the punish- 
ment intensification effect is eliminated when subjects receive temporally spaced brief shocks designed to extinguish the brief shock-strong shock association (Anderson et al., 1997, Experiments 1 and 2). Further, after preexposure to prolonged inescapable shock, the punishment intensification effect can be facilitated when subjects receive a number of closely spaced brief shocks in a single session that would further condition (rather than extinguish) a brief shock-strong shock association (Anderson et al., 1997, Experiment 3). Note that the latter finding is particularly problematic for learned helplessness theory since, after preexposure to prolonged inescapable shock, the additional delivery of inescapable shock should further impair (rather than facilitate) subsequent response-shock learning.

\section{Shock-Shock Associations in Learned Helplessness}

The question then arises as to how shock-shock associations contribute to the escape and avoidance learning deficits shown in learned helplessness studies. At the outset, it is important to be clear that multiple processes, rather than a single process, likely contribute to the deleterious effects of inescapable shock and that preexposure to inescapable shock may result in response initiation, as well as cognitive, deficits (Maier \& Jackson, 1979). However, shock-shock associations may contribute to response initiation deficits.

When subjects are preexposed to prolonged duration shock, shock onset serves as a powerful cue predicting further painful shock. This is supported by the punishment intensification effect, described earlier, and the study by Crowell (1974) showing that weak shock is made more aversive following weak shock-strong shock pairings. Since learned helplessness studies control shock amount (with a yoked design), it must also be assumed that shock onset is made more aversive when paired with inescapable, relative to escapable, shock. When subjects are placed in a novel environment, shock onset will continue to be more aversive for subjects preexposed to inescapable shock. Shock onset will then elicit greater freezing, in inescapably shocked subjects, which will compete with active test responding (see Anisman, DeCatanzaro, \& Remington 1978; Balleine \& Job, 1991; Bracewell \& Black, 1974; Brookshire, Littman, \& Stewart, 1962; but see Anderson, Crowell, Cunningham, \& Lupo, 1979; Maier, 1970). In brief, then, the present account suggests that shock onset cues are made significantly more aversive when paired with inescapable, rather than escapable, shock. Shock onset cues will then elicit greater freezing, in inescapably shocked subjects, which will contribute to subsequent escape and avoidance learning deficits. Note that such an account accommodates the punishment intensification effect, described earlier, since shock onset cues, made aversive when paired with prolonged shock, better punish responding in experimental relative to control subjects.

\section{Shock Duration}

According to the present account, the duration of inescapable shock may be an important factor in subsequent escape and avoidance learning deficits, since the aversiveness of shock onset will be facilitated when shock onset is paired with more prolonged duration shock. In fact, there is evidence that the duration of inescapable shock may be important in subsequent escape and avoidance learning deficits (Anisman et al., 1978; Crowell \& Anderson, 1981; Glazer \& Weiss, 1976). For example, Crowell and Anderson showed greater impairments in escape learning when rats were preexposed to $10-\mathrm{sec}$, rather than 5-sec, inescapable shocks. Further, escape learning did not differ between a group preexposed to 5 -sec inescapable shocks and a no-shock control group (Crowell \& Anderson, 1981). Learned helplessness theory does not readily explain why response-shock noncontingency can be learned with 10-sec but not 5-sec inescapable shocks; in fact, Seligman et al. (1971) suggested that no specific shock parameters, other than inescapability, were required to produce escape deficits. However, if response initiation deficits were facilitated by pairing shock onset with more powerful shock, it is possible that less prolonged shock may reduce the aversive properties conditioned to shock onset cues.

\section{The Shock Duration Order Effect}

In learned helplessness studies, subjects receiving escapable shock generally become faster at escaping shock. Consequently, their yoked partner is exposed to a series of inescapable shocks that tend to decrease in duration over trials. Somewhat surprisingly, if the shocks are presented in the reverse order to the inescapably shocked subject (i.e., the shocks increase rather than decrease in duration), the deleterious effects of inescapable shock are attenuated (see, e.g., Prabhakar \& Job, 1996). This finding is referred to as the shock duration order effect. Note that learned helplessness theory does not readily accommodate the shock duration order effect since the order of inescapable shock, which is simply an artifact of the yoking procedure, does not affect the noncontingent response-shock relation presumed to be responsible for subsequent escape and avoidance learning deficits.

However, the present account may provide an explanation for the shock duration order effect. First, there is evidence that in punishment, gradually increasing shock intensity is less aversive than gradually decreasing shock intensity (Azrin, Holz, \& Hake, 1963; Church, 1969; see also Bolles \& Fanselow, 1982). Indeed, a shock of intermediate intensity can be made more aversive when subjects are preexposed to a high-intensity shock and can be made less aversive when subjects are preexposed to a low-intensity shock (Church, 1969). Therefore, in the shock duration order effect, gradually increasing shock durations may be less aversive than gradually decreasing shock durations. Shock onset cues, therefore, will be paired with more aversive shock when shock durations 
tend to decrease rather than increase. Shock onset cues will then elicit greater freezing in a typical learned helplessness study (when inescapable shock tends to decrease in duration over trials) but will elicit less freezing in the shock duration order effect (when inescapable shock tends to increase in duration over trials).

\section{What Affective Response Is Elicited by Shock Onset Cues?}

Shock onset cues may elicit greater freezing in inescapably shocked subjects, but it is unclear what affective response contributes to this behavioral deficit. Fear is a plausible candidate (Mineka, Cook, \& Miller, 1984; Minor, 1990; Warren, Rosellini, \& Maier, 1989), but a study by Maier (1990) clearly showed that fear was neither necessary nor sufficient for subsequent escape learning impairments. Another possibility is that shock onset cues elicit greater freezing by eliciting certain physiological responses underlying stress or anxiety. This would be compatible with studies demonstrating learned-helplessnesslike effects with uncontrollable appetitive events, which may elicit stress or anxiety rather than fear (see, e.g., Ferguson \& Job, 1997), and with studies showing that learned-helplessness-like effects may transfer across appetitive and aversive contexts (see, e.g., Rosellini, 1978). One difficulty, however, is that learned-helplessness-like effects may dissipate more rapidly with aversive, as opposed to appetitive, stimuli (see, e.g., Ferguson \& Job, 1997; Minor, Dess, \& Overmier, 1991). Further, rapid dissipation effects with shock suggest that the associative effects of freezing elicited by shock onset-strong shock associations may require a sensitization-like effect of shock-elicited stress, or anxiety, to be manifest. Such an outcome suggests that shock onset-strong shock associations may contribute to escape and avoidance learning deficits but cannot be the sole cause of such effects.

\section{SUMMARY}

In certain Pavlovian conditioning procedures, a stimulus normally considered to be a US may have important signaling functions. Such a stimulus may signal the delivery of another US, may block or overshadow the acquisition of CS signal value, or may serve as a modulator for subsequent US delivery or omission. Further, a stimulus normally considered to be a US may signal the approximate time of arrival of a subsequent US, especially when the interval between USs is fixed and short. This timing function may contribute to the attenuated responding shown in contingency manipulations when USs are added to a conditioning session and to the persistent and impaired responding shown in the trial spacing effect with shorter, fixed ITIs. In drug conditioning, a drug may signal the delivery of an identical, or different, drug, and such drug-drug learning may contribute to binge drinking and drug "priming" effects. Finally, shock onset-strong shock associations may arise when prolonged duration shocks are delivered, an outcome that may contribute to the punishment intensification effect, learned helplessness, and the shock duration order effect.

\section{REFERENCES}

Alloy, L. B., \& Tabachnik, N. (1984). Assessment of covariation by humans and animals: The joint influence of prior expectations and current situational information. Psychological Review, 91, 112-149.

ANDERSON, D. C. (1966). Prior shock trauma and test-shock intensity as determinants of escape learning. Psychological Reports, 19, 771-778

ANDERSON, D. C. (1993). Does ACTH mediate the punishmentintensification effect of prolonged, fixed-duration treatment shocks? Psychobiology, 21, 43-49.

Anderson, D. C., Cole, J., \& McVaugh, W. (1968). Variations in unsignaled inescapable preshock as determinants of responses to punishment. Journal of Comparative \& Physiological Psychology Monograph Supplements, 65 (3, Pt. 2), 1-17.

anderson, D. C., Crowell, C. R., Cunningham, C. L., \& Lupo, J. V. (1979). Behavior during shock exposure as a determinant of subsequent interference with shuttle box escape-avoidance learning in the rat. Joumal of Experimental Psychology: Animal Behavior Processes, 5, 243-257.

Anderson, D. C., Crowell, C. R., DePaul, M., \& McEachin, J. (1997). Intensification of punishment effects through exposure to prolonged, fixed-duration shocks: The role of shock cues as a stimulus for fear. Animal Learning \& Behavior, 25, 68-83.

anisman, H., DeCatanzaro, D., \& Remington, G. (1978). Escape performance following exposure to inescapable shock: Deficits in motor response maintenance. Journal of Experimental Psychology Animal Behavior Processes, 4, 197-218.

Atkinson, R. L., Atkinson, R. C., Smith, E. E.. Bem, D. J., \& NolenHoExSEMA, S. (1996). Hilgard 's Introduction to psychology (12th ed.). Fort Worth, TX: Harcourt Brace.

Ayres, J. J. B., Benedict, J. O.. \& Witcher, E. S. (1975). Systematic manipulation of individual events in a truly random control in rats Journal of Comparative \& Physiological Psychology, 88, 97-103.

AzRIN, N. H., Holz, W. C., \& HAKE, D. F. (1963). Fixed-ratio punishment. Journal of the Experimental Analysis of Behavior, 6, 141-148.

BALlEINE, B., \& JOB, R. F. S. (1991). Reconsideration of the role of competing responses in demonstrations of the interference effect (learned helplessness). Journal of Experimental Psychology: Animal Behavior Processes, 17, 270-280.

Best, M. R., \& DOM JAN, M. (1979). Characteristics of the lithiummediated proximal US-preexposure effect in flavor-aversion conditioning. Animal Learning \& Behavior, 7, 433- 440.

Best, M. R., \& Gemberling, G. A. (1977). Role of short-term processes in the conditioned stimulus preexposure effect and the delay of reinforcement gradient in long-delay taste-aversion learning. Journal of Experimental Psychology: Animal Behavior Processes, 3, 253-263.

BLAKEY, R., \& BAKER, R. (1980). An exposure approach to alcohol abuse. Behaviour Research \& Therapy, 18, 319-325.

Bolles. R. C., \& Fanselow, M. S. (1982). Endorphins and behavior. Annual Review of Psychology, 33, 87-101.

BotTJER, S. W., \& HeARst, E. (1979). Food delivery as a conditional stimulus: Feature learning and memory in pigeons. Journal of the Experimental Analysis of Behavior, 31, 189-207.

BraCeWEll, R. J., \& Black, A. H. (1974). The effects of restraint and noncontingent preshock on subsequent escape learning in the rat. Leaming \& Motivation, 5, 53-69.

Brookshire, K. R., Littman, R. A., \& Stewart, C. N. (1962). Residua of shock-trauma in the white rat: A three-factor theory. Psychological Monographs, 75 (10, Whole No. 514), 32.

Cannon, D. S., Berman, R. F., Baker, T. B., \& Atkinson, C. A. (1975). Effect of preconditioning unconditioned stimulus experience on learned taste aversions. Journal of Experimental Psychology: Animal Behavior Processes, 1, 270-284.

CAPALDI, E. J. (1994). The sequential view: From rapidly fading stimulus traces to the organization of memory and the abstract concept of number. Psychonomic Bulletin \& Review, 1, 156-181.

Capaldi, E. J., Alptekin, S., \& Birmingham, K. (1997). Discriminat- 
ing between reward-produced memories: Effects of differences in reward magnitude. Animal Learning \& Behavior, 25, 171-176.

Capaldi, E. J., Alptekin, S., Miller, D. J., \& Birmingham, K. M (1997). Is discriminative responding in reward outcome serial learning mediated by item memories or by position cues? Learning \& $\mathrm{Mo}$ tivation, 28, 153-169.

Capaldi, E. J., \& Birmingham, K. M. (1998). Reward-produced memories regulate memory-discrimination learning, extinction, and other forms of discrimination learning. Journal of Experimental Psychology: Animal Behavior Processes, 24, 254-264.

Church, R. M. (1969). Response suppression. In B. A. Campbell \& R. M. Church (Eds.), Punishment and aversive behavior (pp. 111 156). New York: Appleton-Century-Crofts.

Cole, R. P., Barnet t, R. C., \& Miller, R. R. (1995). Temporal encoding in trace conditioning. Animal Learning \& Behavior, 23, 144-153.

Crowel L, C. R. (1974). Conditioned-aversive aspects of electric shock. Learning \& Motivation, 5, 209-220.

Crowell, C. R., \& ANDERSON, D. C. (1981). Influence of duration and number of inescapable shocks on intrashock activity and subsequent interference effects. Animal Learning \& Behavior, 9, 28-37.

Crowell, C. R., Hinson, R. E., \& Siegel, S. (1981). The role of conditional drug responses in tolerance to the hypothermic effects of ethanol. Psychopharmacology, 73, 51-54.

Davis, H., Herrman, T., MacFadden, L., \& Ellen, P. (1977). Do septal lesions eliminate behavioral control by an autocontingency? Physiological Psychology, 5, 339-342.

Davis, H., \& Memmotт, J. (1984). Autocontingencies: Suppressive and accelerative effects of pairs of shocks superimposed on a positively reinforced operant baseline. Journal of the Experimental Analysis of Behavior, 42, 75-86.

Davis, H., Memmott, J., \& Hurwitz, H. M. B. (1975). Autocontingencies: A model for subtle behavioral control. Journal of Experimen tal Psychology: General, 104, 169-188.

Davis, H., Shattuck, D., \& Wright, J. (1981). Autocontingencies: Factors underlying control of operant baselines by compound tone/shock no-shock contingencies. Animal Learning \& Behavior, 9, 322-331.

Dearing, M. F., \& Dickinson, A. (1979). Counterconditioning of shock by a water reinforcer in rabbits. Animal Learning \& Behavior, 7, 360-366.

DE WIT, H. (1996). Priming effects with drugs and other reinforcers Experimental \& Clinical Psychopharmacology, 4, 5-10.

DE Wit, H., \& ChUTUAPE, M. A. (1993). Increased ethanol choice in social drinkers following ethanol preload. Behavioural Pharmacology, 4, 29-36.

DiCKINSON, A., \& PEARCE, J. M. (1977). Inhibitory interactions between appetitive and aversive stimuli. Psychological Bulletin, 34, 690-711.

DOM JAN, M. (1978). Effects of proximal unconditioned stimulus preexposure on ingestional aversions learned as a result of taste presentation following drug treatment. Animal Learning \& Behavior, 6 133-142

DOM JAN, M., \& BEST, M. R. (1977). Paradoxical effects of proximal unconditioned stimulus preexposure: Interference with and conditioning of a taste aversion. Journal of Experimental Psychology: Animal Behavior Processes, 3, 310-321.

DURLACH, P. J. (1983). Effect of signaling intertrial unconditioned stimuli in autoshaping. Journal of Experimental Psychology: Animal Behavior Processes, 9, 374-389.

DWECK, C. S., \& WAGNER, A. R. (1970). Situational cues and correlation between CS and US as determinants of the conditioned emotional response. Psychonomic Science, 18, 145-147.

EGger, M. D., \& Miller, N. E. (1963). When is a reward reinforcing? An experimental study of the information hypothesis. Journal of Comparative \& Physiological Psychology, 56, 132-137.

FaIllaCe, L. A., Flamer, R. N., IMBER, S. D., \& WARD, R. F. (1972), Giving alcohol to alcoholics: An evaluation. Quarterly Journal of Studies on Alcohol, 33, 85-90

FERGUSON, E. C., \& Joв, R. F. S. (1997). Uncontrollable water deliveries and subsequent finickiness. Animal Learning \& Behavior, 25, 62-67.

Flaherty, C. F., Coppotelli, C., Grigson, P. S., Mitchell, C. \& FLAHERTY, J. E. (1995). Investigation of the devaluation interpreta- tion of anticipatory negative contrast. Journal of Experimental Psychology: Animal Behavior Processes, 21, 229-247.

GamzU, E. R., \& WiLliams, D. R. (1973). Associative factors underlying the pigeon's key pecking in autoshaping procedures. Journal of the Experimental Analysis of Behavior, 19, 225-232.

GARCIA, J. (1989). Food for Tolman: Cognition and cathexis in concert. In T. Archer \& L.-G. Nilsson (Eds.), Aversion, avoidance, and anxiety: Perspectives on aversively motivated behavior (pp. 45-85). Hillsdale, NJ: Erlbaum.

GrbBon, J. (1981). The contingency problem in autoshaping. In C. M. Locurto, H. S. Terrace, \& J. Gibbon (Eds.), Autoshaping and conditioning theory (pp. 285-308). New York: Academic Press.

Gibbon, J., Baldock, M. D., Locurto, C., Gold, L., \& TERrace, H. S. (1977). Trial and intertrial durations in autoshaping. Journal of Experimental Psychology: Animal Behavior Processes, 3, 264-284

GiBBON, J., \& BALSAM, P. (1981). Spreading association in time. In C. M. Locurto, H. S. Terrace, \& J. Gibbon (Eds.), Autoshaping and conditioning theory (pp. 219-253). New York: Academic Press.

GibBon, J., LocurTo, C. M., \& TerRaCe, H. S. (1975). Signal-food contingency and signal frequency in a continuous trials auto-shaping paradigm. Animal Learning \& Behavior, 3, 317-324.

Glazer, H. I. \& Weiss, J. M. (1976). Long-term interference effect: An alternative to "learned helplessness." Journal of Experimental Psychology: Animal Behavior Processes, 2, 202-213.

Gleitman, H. (1995). Psychology (4th ed.). New York: W. W. Norton.

GODDARD, M. J. (1991). US-US associations as a factor in the habituation to emotionally arousing stimuli. Motivation \& Emotion, 15 207-219.

GodDard, M. J. (1995). Acquisition of US-no US associations in Pavlovian conditioning. Learning \& Motivation, 26, 264-277.

GODDARD, M. J. (1996). Effect of US signal value on blocking of a CSUS association. Journal of Experimental Psychology: Animal Behavior Processes, 22, 258-264.

GodDaRD, M. J. (1997). Spontaneous recovery in US extinction. Learning \& Motivation, 28, 118-128.

GoDDARD, M. J. (1999). Renewal to the signal value of an unconditioned stimulus. Learning \& Motivation, 30, 15-34.

GodDaRd, M. J., \& Allan, L. (1988). A critique of Alloy and Tabachnik's theoretical framework for understanding covariation assessment. Psychological Review, 95, 296-298.

Goddard, M. J., \& Holland, P. C. (1996). Type of feature affects transfer in operant serial feature-positive discriminations. Animal Learning \& Behavior, 24, 266-276.

GodDaRD, M. J., \& Holland, P. C. (1997). The effects of feature identity in operant serial feature-negative discriminations. Learning \& Motivation, 28, 577-608

Goddard, M. J., Holland, M., O'Brien, J., \& Hansen, D. (1994). Improving conditioning with unsignaled, but not signaled, unconditioned stimuli. Learning \& Motivation, 25, 288- 312.

GodDaRD, M. J., \& JeNKINS, H. M. (1987). Effect of signaling extra unconditioned stimuli on autoshaping. Animal Learning \& Behavior, $15,40-46$.

GodDARD, M. J., \& JENKINS, H. M. (1988). Blocking of a CS-US association by a US -US association. Journal of Experimental Psychology: Animal Behavior Processes, 14, 177- 186

Greeley, J., Le, D. A., Poulos, C. X., \& Cappell, H. (1984). Alcohol is an effective cue in the conditional control of tolerance to alcohol. Psychopharmacology, 83, 159-162.

GunTher, L. M., Miller, R. R., \& Matute, H. (1997). CSs and USs: What's the difference? Journal of Experimental Psychology: Animal Behavior Processes, 23, 15-30.

HiNSON, R. E., \& SiEgel, S. (1982). Nonpharmacological bases of drug tolerance and dependence. Journal of Psychosomatic Research, 26, 495-503.

HoDGSON, R. J., \& RankIN, H. J. (1976). Modification of excessive drinking by cue exposure. Behaviour Research \& Therapy, 14, 305-307.

Hodgson, R. J., Rankin, H. J., \& Stockwell, T. (1979). Alcohol dependence and the priming effect. Behaviour Research \& Therapy, 17, 379-387

Holland, P. C., \& Forbes, D. T. (1982). Control of conditional dis- 
crimination performance by $\mathrm{CS}$-evoked event representations. Animal Learning \& Behavior, 10, 249-256.

Hollis, K.L. \& Overmier, J. B. (1973). Effective inescapable shock on efficacy of punishment of appetitive responding by dogs. Psychological Reports, 33, 903-906.

JELLINEK, E. M. (1960). The disease concept of alcoholism. New Haven, CT: Hillhouse Press.

Jenkins, H. M., Barnes, R. A., \& Barrera, F. J. (1981). Why autoshaping depends on trial spacing. In C. M. Locurto, H. S. Terrace, \& J. Gibbon (Eds.), Autoshaping and conditioning theory (pp. 255284). New York: Academic Press.

Jenkins, H. M. \& ShatTuck, D. (1981). Contingency in fear conditioning: A reexamination. Bulletin of the Psychonomic Society, 17, $159-162$.

JONES, B. M. (1974). Circadian variation in the effects of alcohol on cognitive performance. Quarterly Journal of Studies on Alcohol, 35, 1212-1219

KAMIN, L. J. (1965). Temporal and intensity characteristics of the conditioned stimulus. In W. F. Prokasy (Ed.), Classical conditioning: $A$ symposium (pp. 118-147). New York: Appleton-Century-Crofts.

KAMIN, L. J. (1968). "Attention-like" processes in classical conditioning. In M. R. Jones (Ed.), Miami Symposium on the Prediction of Behav ior, 1967. Aversive stimulation (pp. 9-31). Coral Gables, FL: University of Miami Press.

Kamin, L. J. (1969). Predictability, surprise, attention and conditioning. In B. A. Campbell \& R. M. Church (Eds.), Punishment and aversive behavior (pp. 279-329). New York: Appleton-Century-Crofts.

Kamin, L. J., \& SCHAub, R. E. (1963). Effects of conditioned stimulus intensity on the conditioned emotional response. Journal of Comparative \& Physiological Psychology, 56, 502-507.

KLEIN, S. B. (1996). Learning principles and applications (3rd ed.) New York: McGraw-Hill.

KonORSKI, J., \& LAWICKA, W. (1959). Physiological mechanism of delayed reactions: $I$. The analysis and classification of delayed reactions. Acta Biologiae Experimentalis, 19, 175-197.

Kurtz, J. H., \& Pearl, J. (1960). The effects of prior fear experience on acquired-drive learning. Journal of Comparative \& Physiological Psychology, 53, 201-206.

LAMBOS, W. A. (1986). Blocking and the prevention of blocking from the unconditioned stimulus in Pavlovian conditioning. Unpublished doctoral dissertation, McMaster University.

LE, A. D., Poulos, C. X., \& CAPPEll, H. (1979). Conditioned tolerance to the hypothermic effect of ethyl alcohol. Science, 206, 1109-1110.

LETT, B. T. (1983). Pavlovian drug-sickness pairings result in the conditioning of an antisickness response. Behavioral Neuroscience, 97 779-784.

Ludwig, A. M., \& STARK, L. H. (1974). Alcohol craving: Subjective and situational aspects. Quarterly Journal of Studies on Alcohol, 35 108-130.

Ludwig, A. M., Wikler, A., \& STark, L. H. (1974). The first drink: Psychobiological aspects of craving. Archives of General Psychiatry, 30, 539-547.

MACKINTOSH, N. J. (1971). An analysis of overshadowing and blocking Quarterly Journal of Experimental Psychology, 23, 118-125.

Mackintosh, N. J., \& Reese, B. (1979). One-trial overshadowing. Quarterly Journal of Experimental Psychology, 31, 519-526.

MAIER, S. F. (1970). Failure to escape traumatic electric shock. Learning \& Motivation, 1, 157-169.

MAIER, S. F. (1989). Learned helplessness: Event covariation and cognitive changes. In S. B. Klein \& R. R. Mowrer (Eds.), Contemporary learning theories: Instrumental conditioning theory and the impact of biological constraints on learning (pp. 73-110). Hillsdale, NJ: Erlbaum.

MAIER, S. F. (1990). Role of fear in mediating shuttle escape learning deficit produced by inescapable shock. Journal of Experimental Psychology: Animal Behavior Processes, 16, 137-149.

MAIER, S. F., \& JACkson, R. L. (1979). Learned helplessness: All of us were right (and wrong): Inescapable shock has multiple effects. In G. H. Bower (Ed.), The psychology of learning and motivation (Vol. 13, pp. 155-218). New York: Academic Press.

Maier, S. F., Seligman, M. E. P., \& Solomon, R. L. (1969). Pavlovian fear conditioning and learned helplessness: Effects on escape and avoidance behavior of (a) the CS-US contingency, and (b) the independence of the US and voluntary responding. In B. A. Campbell \& R. M. Church (Eds.), Punishment (pp. 299-342). New York: AppletonCentury-Crofts.

Mansfield, J. E., \& Cunningham, C. L. (1980). Conditioning and ex tinction of tolerance to the hypothermic effect of ethanol in rats. Jour nal of Comparative \& Physiological Psychology, 94, 962-969.

Marconi, J., Fink, K., \& Moya, L. (1967). Experimental study on alcoholics with an "inability to stop." British Journal of Psychiatry, 113 543-545.

Mathew, R. J., Claghorn, J. L., \& Largen, J. (1979). Craving for alcohol in sober alcoholics. American Journal of Psychiatrv, 136, 603-606.

Melchior, C. L., \& TABaKoff, B. (1981). Modification of environmentally cued tolerance to ethanol in mice. Journal of Pharmacology \& Experimental Therapeutics, 219, 175-180.

Miller, R. R., \& MATzEL, L. D. (1988). The comparator hypothesis: A response rule for the expression of associations. In G. H. Bower (Ed.), The psychology of learning and motivation: Advances in research and theory (Vol. 22, pp. 51-92). San Diego: Academic Press.

Mineka, S., CoOK, M., \& Miller, S. (1984). Fear conditioned with escapable and inescapable shock: Effects of a feedback stimulus. Journal of Experimental Psychology: Animal Behavior Processes, 10. 307-323.

Minor, T. R. (1990). Conditioned fear and neophobia following inescapable shock. Animal Learning \& Behavior, 18, 212-226.

Minor, T. R., Dess, N. K., \& Overmier J. B. (1991). Inverting the traditional view of "learned helplessness": Reinterpretation in terms of anxiety and modulator operations. In M. R. Denny (Ed.), Fear, avoidance, and phobias: A fundamental analysis (pp. 87-113). Hillsdale, NJ: Erlbaum.

MitcheLl, D. S. (1974). Conditional responding and intertrial-interval variability in classical conditioning in the rabbit (Orvctolagus cuniculus). Journal of Comparative \& Physiological Psychology, 87, 73-79.

Mitchell, S. H., DE WIT, H., \& ZaCNY, J. P. (1995). Effects of varying ethanol dose on cigarette consumption in healthy normal volunteers Behavioural Pharmacologv, 6, 359-365

NAGEISHI, Y., \& IMADA, H. (1974). Suppression of licking behavior in rats as a function of predictability of shock and probability of conditioned-stimulus-shock pairings. Journal of Comparative \& Physiological Psychology, 87, 1165-1173.

Papini, M. R., \& Bitterman, M. E. (1990). The role of contingency in classical conditioning. Psychological Review, 97, 396-403.

Paredes, A., Gregory, D., \& Jones, B. M. (1974). Induced drinking and social adjustment in alcoholics. Development of a therapeutic mode. Quarterly Journal of Studies on Alcohol, 35, 1279-1293.

Paredes, A., Hood, W. R., Seymour, H., \& Gollob, M. (1973). Loss of control in alcoholism. An investigation of the hypothesis, with experimental findings. Quarterly Journal of Studies on Alcohol, 34, 1146-1161,

Pavlov, I. P. (1927). Conditioned reflexes (G. V. Anrep, Trans.). London: Oxford University Press.

Pearce, J. M., \& Dickinson, A. (1975). Pavlovian counterconditioning: Changing the suppressive properties of shock by association with food. Journal of Experimental Psychology: Animal Behavior Processes, 104, 170-177

Pearl, J., Walters, G. C., \& Anderson, D. C. (1964). Suppressing effects of aversive stimulation on subsequently punished behavior. Canadian Journal of Psychology, 18, 343-355.

Perkins, Jr, C. C., Beavers, W. O., Hancock, JR., R. A., HemMendinger, P. C., Hemmendinger, D., \& RicCi, J. S. (1975). Some variables affecting rate of key pecking during response-independent procedures (autoshaping). Journal of the Experimental Analysis of Behavior, 24, 59-72.

Prabhakar, T., \& Job, R. F. S. (1996). The effects of order of shock durations on helplessness in rats. Animal Learning \& Behavior, 24, 175-182.

Prokasy, W. F. (1965). Stimulus fluctuation, reactive inhibition, and time between trials in classical eyelid conditioning. Journal of Experimental Psychology, 70, 464-472. 
Prokasy, W. F., Grant, D. A., \& Myers, N. A. (1958). Eyelid conditioning as a function of unconditioned stimulus intensity and intertrial interval. Journal of Experimental Psychology, 55, 242-246.

Reberg, D., \& MEMmotr, J. (1979). Shock as a signal for shock or noshock: A feature-negative effect in conditioned suppression. Journal of the Experimental Analysis of Behavior, 32, 387-397.

ResCorla, R. A. (1968). Probability of shock in the presence and absence of CS in fear conditioning. Journal of Comparative \& Physiological Psychology, 66, 1-5.

ResCorla, R. A., \& Furrow, D. R. (1977). Stimulus similarity as a determinant of Pavlovian conditioning. Journal of Experimental Psychology: Animal Behavior Processes, 3, 203-215.

ResCoRLA, R. A., \& WAGNER, A. R. (1972). A theory of Pavlovian conditioning: Variations in the effectiveness of reinforcement and nonreinforcement. In A. H. Black \& W. F. Prokasy (Eds.), Classical conditioning II: Current research and theory (pp. 64-99). New York: Appleton-Century-Crofts.

REvUSKY, S. (1985). Drug interactions measured through taste aversion procedures with an emphasis on medical implications. In N. S. Braveman \& P. Bronstein (Eds.), Experimental assessments and clinical applications of conditioned food aversions (Annals of the New York Academy of Sciences, Vol. 443, pp. 250-271). New York: New York Academy of Sciences.

RoseLLINI, R. A. (1978). Inescapable shock interferes with the acquisition of an appetitive operant. Animal Learning \& Behavior, 6, 155-159.

Salafia, W. R., Mis, F. W., Terry, W. S., Bartosiak, R. S., \& Daston, A. P. (1973). Conditioning of the nictitating membrane response of the rabbit (Oryctolagus cuniculus) as a function of length and degree of variation of intertrial interval. Animal Learning \& Behavior, 1, $109-115$.

Schreurs, B. G., \& AlKon, D. L. (1990). US-US conditioning of the rabbit's nictitating membrane response: Emergence of a conditioned response without alpha conditioning. Psychobiology, 18, 312-320.

SchWARTz, B., \& RobBins, S. J. (1995). Psychology of learning and behavior (4th ed.). New York: W. W. Norton.

Seligman, M. E. P., \& Maier, S. F. (1967). Failure to escape traumatic shock. Journal of Experimental Psychology, 74, I-9.

Seligman, M. E. P., Maier, S. F., \& Solomon, R. L. (1971). Unpredictable and uncontrollable aversive events. In F. R. Brush (Ed.) Aversive conditioning and learning (pp. 347-400). New York: Academic Press.

SIEGEL, S. (1983). Classical conditioning, drug tolerance, and drug dependence. In R. G. Smart, F. B. Glaser, Y. Israel, H. Kalant, R. E. Popham, \& W. Schmidt (Eds.), Research advances in alcohol and drug problems (Vol. 7, pp. 207-246). New York: Plenum.

SIEGEL, S. (1990). Classical conditioning and opiate tolerance and withdrawal. In D. J. K. Balfour (Ed.), Psychotropic drugs of abuse. International encyclopedia of pharmacology and therapeutics (pp. 5985). Elmsford, NY: Pergamon.

Siegel, S., \& Allan, L. G. (1998). Learning and homeostasis: Drug addiction and the McCollough effect. Psychological Bulletin, 124, 230-239.

Siegel, S., Krank, M. D., \& Hinson, R. E. (1987). Anticipation of pharmacological and nonpharmacological events: Classical conditioning and addictive behavior. Journal of Drug Issues, 17, 83-110.
Skinner, D. M., Goddard, M. J., \& Holland, P. C. (1998). What can nontraditional features tell us about conditioning and occasionsetting? In N. A. Schmajuk \& P. C. Holland (Eds.), Occasion-setting. Associative learning and cognition in animals (pp. 113-144). Washington, DC: American Psychological Association.

STEIN, L. I. (1966). Habituation and stimulus novelty: A model based on classical conditioning. Psychological Review, 73, 352-356.

Stein, L. I., Niles, D., \& LudWig, A. M. (1968). The loss of control phenomenon in alcoholics. Quarterly Journal of Studies on Alcohol, $29,598-602$

STEWART, J. (1992). Neurobiology of conditioning to drugs of abuse. In P. W. Kalivas \& H. H. Samson (Eds.), The neurobiology of drug and alcohol addiction (Annals of the New York Academy of Sciences, Vol. 654, pp. 335-346). New York: New York Academy of Sciences.

TAUKULIS, H. K. (1982). Attenuation of pentobarbital-elicited hypothermia in rats with a history of pentobarbital-LiCl pairings. Pharmacology, Biochemistry \& Behavior, 17, 695-697.

TAUKULIS, H. K. (1986). Conditional shifts in thermic responses to sequentially paired drugs and the "conditional hyperactivity" hypothesis. Pharmacology, Biochemistry \& Behavior, 25, 83-87.

TAUKULIS, H. K. (1996). Pavlovian conditioning to a diazepam cue with yohimbine as the unconditioned stimulus. Neurobiology of Learning \& Memory, 65, 223-232.

TERRY, W. S., \& WAGNER, A. R. (1975). Short-term memory for "surprising" versus "expected" unconditioned stimuli in Pavlovian conditioning. Journal of Experimental Psychology: Animal Behavior Processes, 1, 122-133.

TESTA, T. J. (1975). Effects of similarity of location and temporal intensity pattern of conditioned and unconditioned stimuli on the acquisition of conditioned suppression in rats. Journal of Experimental Psychology: Animal Behavior Processes, 104, 114-121.

TUBER, D. S. (1986). Dominance, the bidirectional hypothesis, and Pavlovian backward conditioning in the US-US paradigm. Animal Learning \& Behavior, 14, 421-426.

van Hest, A., van Haaren, F., Kop, P., \& van der Schoot, F. (1986). Stimulus- and feeder-directed behavior in a long-box: Effect of fixed versus variable time schedules of food presentation. Animal Learning \& Behavior, 14, 168-172.

WAGNER, A. R., \& BRANDON, S. E. (1989). Evolution of a structured connectionist model of Pavlovian conditioning (AESOP). In S. B. Klein \& R. R. Mowrer (Eds.), Contemporary learning theories: Pavlovian conditioning and the status of traditional learning theory (pp. 149189). Hillsdale, NJ: Erlbaum.

Walters, G. C., \& Rogers, J. V. (1963). Aversive stimulation of the rat: Long-term effects on subsequent behavior. Science, 142, 70-71.

WARren, D. A., Rosellini, R. A., \& MaIER, S. F. (1989). Fear, stimulus feedback, and stressor controllability. In G. H. Bower (Ed.), The psychology of learning and motivation (Vol. 24, pp. 167-207). Orlando, FL: Academic Press.

(Manuscript received January 27, 1998 revision accepted for publication September 18, 1998.) 